\title{
El derecho como fenómeno político \\ Crítica de la interpretación estándar en la filosofía del derecho respecto de la relación entre el Derecho y la Política
}

\author{
Law as a political phenomenon \\ Critique of the standard interpretation in the philosophy of law concerning the \\ relation between Law and Politics
}

Alessandro Caviglia Marconi ${ }^{1}$

\section{RESUMEN}

El presente trabajo presenta una crítica a la concepción sobre el derecho que señalaque este es completamente autónomo de la política y de la moral. Esta concepción ha sido construida por el positivismo jurídico y ha sido absorbida tanto por el neoconstitucionalismo y la teoría de la argumentación jurídica. Frente a esta visión del derecho, se presenta una concepción del derecho caracterizada por la reflexión y que afirma la idea de que el derecho no solo se encuentra conectado con la política, sino que brota del suelo de la política misma. Para ello se utilizarán los avances en la reflexión sobre la justicia, la política y el derecho realizados en la actual escuela de Frankfurt.

\section{Palabras clave}

Derecho, política, moral, justicia, teoría crítica de la sociedad, positivismo jurídico, neoconstitucionalismo, teoría de la argumentación jurídica, Rainer Forst, Hans Kelsen, Carlos Santiago Nino.

\begin{abstract}
This work reviews the concept of right, pointing out that it is completely autonomous from politics and moral. This concept has been formulated by juridical positivism and absorbed by neoconstitutionalism and the theory of juridical argumentation. Opposite to this vision of right, the concept of law introduced is characterized by the reflection and states that the idea that law is not only connected with politics but also comes out from the politics itself. Consequently, progress made in the current school of Frankfurt on the reflection about justice, politics and law will be used.
\end{abstract}

\section{Keywords}

Right, politics, moral, justice, critical theory of society, juridical positivism, neoconstitutionalism, juridical argumentation theory, Rainer Forst, Hans Kelsen, Carlos Santiago Nino.

Cuando se ha pensado la relación entre el derecho y la política, se han asumido dos posiciones extremas entre las cuales ha sido presentada una serie de alternativas intermedias. La primera de estas posiciones extremas plantea la necesaria desconexión entre ambas dimensiones, mientras que la segunda defiende la relación entre ellas. Entre ambas posiciones, se encuentran aquellas que sostienen una conexión relativa o una conexión arbitraria. En el presente trabajo, buscaré mostrar cómo los esfuerzos por abordar esta

\footnotetext{
Magíster en filosofía por la Pontificia Universidad Católica del Perú. Profesor de la carrera de Filosofía de la Universidad Antonio Ruiz de Montoya, profesor del Departamento de Humanidades de la Universidad Ricardo Palma y profesor de la Facultad de Derecho de la Universidad San Martín de Porres. Ha publicado diversos artículos y ha presentado numerosas ponencias.
} 
cuestión han fracasado sistemáticamente, debido a la poca ilustración filosófica que han tenido los contendientes.

\section{1.- La interpretación estándar en la filosofía del derecho respecto de la conexión entre el derecho y la política}

La posición más extendida respecto al problema de la relación entre derecho $y$ política ha sido el positivismo, que desde John Austin (en el siglo XIX), pasando por Hans Kelsen (en el siglo XX) y reeditándose bajo las formas de positivismo inclusivo, positivismo metodológico, neoconstitucionalismo o teoría de la interpretación jurídica, entre otras variantes que pululan en las escuelas de derecho, se ha seguido manteniendo la premisa básica según la cual el derecho necesita articular un discurso autónomo. Esta exigencia de la autonomía del discurso jurídico tomó una gran importancia desde que Kelsen exigió que el derecho devenga en una ciencia, análoga a la física o las ciencias sociales, y por ello debe expulsar tanto la moral, la política como la justicia y declarar que éstas no son más que ideología ${ }^{2}$.

Si bien, los seguidores contemporáneos de Kelsen han amenguado el discurso cientificista -aunque no lo han abandonado del todo-, han mantenido la misma exigencia de Kelsen, pero ahora enarbolando la bandera de la autonomía del discurso jurídico. De acuerdo a esta exigencia, el derecho tendía un discurso propio y originario que no se derivaría ni de la política, ni de la moral, ni de la religión o de ninguna otra fuente normativa. La normatividad propia del derecho le viene de sus procedimientos y principios que han sido generados por el mismo derecho y que no dependen de ninguna otra fuente normativa. De esta manera, el derecho tendría un discurso que se genera a sí mismo, es decir, autopoiético. De esta manera, el derecho se convierte en un sistema normativo autónomo que, por un lado (a) descomplica la toma de decisiones de las personas en sociedades complejas ${ }^{3}$ (b) se autogenera a sí mismo.

Como puede observarse, uno puede seguir afirmando (a), es decir, que el derecho es un sistema normativo autónomo sin la necesidad de comprometerse con la afirmación (b), según la cual el derecho es autopoiético. Perfectamente se puede mantener la idea del derecho como un sistema normativo autónomo y afirmar, a la vez, que su validez normativa proviene de fuera del derecho mismo, como, por ejemplo, de la moral o de la política. Todas las versiones del positivismo jurídico defienden la autonomía del discurso jurídico, de forma que la afirmación (a) y (b) se confunden de tal manera que afirmar que el derecho es un sistema normativo autónomo los lleva a asumir que ello significa que necesariamente la validez normativa del derecho proviene de sí mismo. Como se puede observar, no basta con afirmar la identidad entre (a) y (b), sino que es necesario demostrar que esta es real. Lo que sucede es que los defensores de toda forma de positivismo jurídico asumen esa identidad como un factum del cual no es necesario dar razones. Con esto, lo que queda claro es que el positivismo ha detenido la reflexión. Pero una filosofía del derecho suficientemente reflexiva puede dar cuenta del dogmatismo en el que el positivismo se encuentra entrampado.

Es posible que algunos positivistas se den cuenta de que su posición es dogmática y que requieren de mayor reflexión, pero deciden no emprenderla pues consideran que con lo que tienen basta y sobra, por decirlo de algún modo, para la práctica cotidiana del abogado. Es como quien afirmó en una oportunidad que "puedo ver las deficiencias del test de ponderación de Robert Alexy, pero lo seguiré usando porque lo considero útil para la práctica". Quien piensa de este modo está declarando que renuncia a la reflexividad propia de la filosofía del derecho en aras de una supuesta eficacia en su desempeño como abogado.

\footnotetext{
Véase al respecto KELSEN, Hans; Teoría pura del derecho, México: UNAM, 1983.

3 Al respecto, véase LUHMANN, Niklas; Sistemas sociales. Lineamientos para una teoría general, Barcelona: Anthopos, 1998.
} 
Otra forma de detener la reflexión proviene de aquellos filósofos y abogados que consideran que el problema central de la filosofía del derecho lo constituye la epistemología jurídica. Hay muchos abogados y filósofos dedicados a investigar el estatuto epistemológico de las afirmaciones jurídicas. Esta actitud constituye una forma de comprometerse con la autonomía del discurso jurídico tal como la entienden los positivistas. De hecho, la pregunta por el estatuto epistemológico del derecho es una reedición de la preocupación de la cientificidad del derecho. El enfoque que estoy cuestionando no yerra porque considera que haya problemas epistémicos en el derecho que vale la pena investigar, sino porque considera que estos problemas constituyen los centrales y los únicos que valen la pena. Desde esta óptica, lo que hacen es declarar que los problemas políticos o morales del derecho no tienen lugar y toda investigación sobre ellos debe ser expulsada de la filosofía del derecho.

\section{2.- La interpretación fallida de la conexión entre el derecho y la moral}

$\mathrm{Si}$ en positivismo, en todas sus formas, desconecta el derecho de la moral apelando a la idea de que el derecho debe abandonar la autonomía de su discurso, hay una posición que afirma la conexión entre estas dimensiones pero que no abandona los presupuestos del positivismo. El argentino Carlos Santiago Nino abogó por una conexión de esta clase. Su posición sostiene que tanto el derecho, como la moral y la política son discursos autónomos, pero que encuentran puntos de encuentro, y sobre la base de ellos es que se busca avanzar en la superación del positivismo ${ }^{4}$. Sin embargo, esta solución tiene algunos problemas, entre los que destacan dos. En primer lugar, asume los presupuestos positivistas al momento de pensar el derecho, de tal manera que lo interpreta con las mismas claves que una el positivismo. Lo que creía Nino era que se podía mantener los presupuestos positivistas y hacer que el derecho, la política y la moral tuviesen puntos de intersección. Esto mismo constituye el otro problema fundamental. No es posible resolver el problema de la desconexión entre derecho y política buscando solo puntos de intersección, el decir, que no basta con decir que para ciertas situaciones complejas el derecho de por sí no basta y se requiere conectarlo con la política, como en ciertos casos de justicia constitucional.

La posición del jurista argentino en esta cuestión coincide con la del neoconstitucionalismo, que sostiene que hay casos jurídicos, como los de la ley de consulta previa o la actividad propia del Tribunal Constitucional, cuyas funciones son jurídicas y políticas al mismo tiempo. En casos como el de la consulta previa, se sostiene, no se puede proceder de la misma manera que en un caso de compra-venta, sino que debe ponerse en acción los principios que aparecen en la Constitución. Pero, como la constitución tiene una doble naturaleza, a saber, jurídica y política, es allí donde entraría en juego la coordinación entre el derecho y la política. Pero aquí, en neoconstitucionalismo, realiza una remisión limitada, pues considera que el margen de la actividad política posible es la misma Constitución, que es una norma positiva. Es decir, el debate político tiene su tope enmarcado por el derecho (representado por la Constitución). Así, en debate político no es abierto y cuenta con las alas recortadas, y con ello la conexión entre el derecho y la política se da a través de una intersección.

$\mathrm{Ni}$ la posición de Nino ni la del neoconstitucionalismo ofrecen una solución satisfactoria a la cuestión de la conexión entre el derecho y la política. La razón de ello se encuentra en que no han ejercido una reflexión suficiente respecto del derecho. Su escasa ilustración filosófica es la causa de esa falta de reflexión. Al asumir como puntos de partida las premisas del positivismo, especialmente la de la autonomía del discurso jurídico, adoptan posiciones dogmáticas que no permiten el desarrollo de una filosofía del derecho reflexiva que sea capaz de explorar las razones de los presupuestos de tales posiciones dogmáticas. Por esta razón, requerimos de una filosofía del derecho reflexiva para poder entender que la

4 Cf. NINO, Carlos Santiago; Derecho, moral y política: una revisión de la teoría general del derecho, Barcelona: Editorial Ariel, 1994. 
mejor forma posible de establecer la conexión entre el derecho y la política es mostrando que el derecho es un fenómeno de la política.

\section{3.- El derecho como fenómeno político}

Hay dos formas en las cuales alguien puede afirmar que el derecho es un fenómeno de la política. La primera es sosteniendo que la política consiste en el juego de fuerzas entre partes que buscan tener mayor cuota de poder. En este sentido, los grupos (o clases, para utilizar el lenguaje marxista) dominantes determinan el derecho. La crítica de Marx al derecho va en este sentido. Él señala que el derecho constituye una ideología pues, por un lado, se presenta como la herramienta que permite garantizar los derechos de todos cuando en realidad constituye un mecanismo que sirve para justificar la relación de dominación injusta. La prueba de ello la encuentra Marx en el hecho de que en las sociedades burguesas el derecho central lo constituye el de la propiedad privada. Todo el sistema jurídico, en ese tipo de sociedad, se articula en torno a ese derecho y se presenta como un sistema que garantiza las libertades de todos. Sin embargo, la propiedad se encuentra distribuida de tal manera que se encuentra concentrada en una clase que tiene pocos miembros, mientras que el resto de la sociedad se encuentra desposeída. De modo que el derecho protege sólo los intereses de una clase y no las libertades de todos.

Como se puede observar, el realismo político de Marx arroja un saldo completamente negativo a la hora de evaluar la relación entre el derecho y la política. Él presenta la idea de que el derecho es un fenómeno de la política, pero interpreta esta última como un juego de fuerzas. La posición de Carl Schmitt capitalizará el realismo político para sus fines reaccionarios, pero hará uso de la misma lógica ${ }^{5}$. Pero, es posible darle un giro de timón a la idea de que el derecho es un fenómeno de la política si asumimos una filosofía política reflexiva. El problema de Marx y Schmitt consiste en que sus concepciones de la política carecen de la iluminación filosófica suficiente como para estar apoyadas en una filosofía política crítica y reflexiva. Es por esta razón que pasaremos a una concepción del derecho como fenómeno de la política desde una filosofía crítica y reflexiva.

\section{1.- El derecho como fenómeno político desde una filosofía política crítica y reflexiva}

Una filosofía política crítica y reflexiva realiza una distinción de planos importante respecto de la política. De una parte, percibe la política desde un punto de vista fáctico de la razón teórica, como relaciones de poder. De otra parte, entiende la política desde el punto de vista de la razón práctica, como despliegue y organización pública de la libertad. La distinción entre razón teórica y razón práctica presentada aquí es la misma que Kant asume desde la Crítica de la razón pura. Para Kant, la razón es una pero tiene dos usos, uno teórico y otro práctico. El uso teórico de la razón se refiere al conocimiento de las cosas dentro del marco de la experiencia en tanto fenómenos. Pero, como la razón misma se hace preguntas que desbordan los límites de la experiencia, el uso práctico piensa esas cuestiones y postula ideas o piensa el noumeno. Ello no quiere decir que los objetos del pensamiento de la razón práctica sean objetos de conocimiento. Tampoco son arbitrarios, puesto que la razón requiere pensarlos para dotar de coherencia a las experiencias. Esta distinción entre uso teórico y práctico de la razón, y la consecuente distinción entre fenómeno y noumeno caracterizan a la filosofía crítica inaugurada por Kant. La filosofía crítica opera por medio de una reflexión suficiente para poder enfrentar las antinomias ante las cuales la filosofía precrítica se ha encontrado enfrentada. De esta manera, la filosofía crítica es necesariamente reflexiva. Esta reflexividad se expresa en la realización del conocido giro copernicano.

Si bien, se trata de una sola razón que tiene dos usos diferentes, nosotros nos referiremos a ambos usos como "razón teórica" y "razón práctica". Tal como Kant lo señala con claridad

\footnotetext{
5 Mientras que Marx utiliza el realismo político para superar a la sociedad capitalista y avanzar en el despliegue de la historia Schmitt lo hace para cuestionar la sociedad liberal e intentar dar marcha atrás al reloj de la humanidad.
} 
en la primera crítica, "práctico es todo lo que se realiza por medio de la libertad". De esta manera, a diferencia del uso habitual de la palabra, práctico no tiene que ver con la resolución de problemas como el reparar un artefacto eléctrico. Este último no es un problema práctico sino técnico. Lo práctico tiene que ver, más bien, el considerar a las personas como libres, es decir autónomas, como fines en sí mismas. De esta manera, la libertad y la autonomía son términos centrales en este giro reflexivo de la filosofía y son centrales para una filosofía política crítica y reflexiva.

Con esto, se abre una distinción crítica y reflexiva del poder, entendido como un elemento central de la política. Esta distinción, desarrollada por Rainer Forst ${ }^{6}$, es entre poder fenoménico y poder nouménico. Por poder fenoménico entiende el poder fáctico, que es el poder que carece de justificación por medio de razones sin que prevalezca por medio de la fuerza. En cambio, por poder nouménico entiende Forst aquel que brota de la justificación por razones. Esta distinción se encuentra acompañada de aquella otra que distingue el poder de la justificación del poder. El poder de la justificación es aquel que se articula por medio del consentimiento de los involucrados. Dicha articulación se consigue por medio de lo que Forst denomina derecho a la justificación. Este es el que asiste a toda persona que se encuentra sujeta a un esquema normativo y le da la posibilidad de exigir que se le justifique, por medio de razones, las normas que él considera injustas. De esta manera, el poder nouménico se constituye a través del derecho a la justificación. En cambio, cuando se le niega a alguien el derecho a la justificación lo que se ejerce es dominación injusta. Y cuando se impide a las personas que ejerzan su derecho a la justificación difundiendo entre ellos la creencia en un orden metafísico espeso que les señala que el orden normativo ha sido creado y querido por los dioses (como en el caso del virreinato peruano), entonces se ejerce una dominación injusta apoyada en una ideología 7 .

\section{2.- Dos imágenes de la justicia y del derecho}

En Justificación y crítica Forst distingue dos imágenes de la justicia. La teoría de del filósofo de la escuela de Fráncfort nos resultará importante para poder ver con claridad la relación más adecuada entre el derecho y la política, pues nos proporciona una filosofía política suficientemente reflexiva.

\subsection{1.- La primera imagen de la justicia y del derecho}

La primera imagen de la justicia es una "determinada interpretación del antiguo principio de la comprensión de la justicia, suun cuique Śa cada cual lo suyoṢ, que es central desde Platón, y que se interpreta como como que en primer lugar importa lo que le corresponde a los individuos, en bienes, con arreglo a la justicia, es decir, quién "obtiene" qué". ${ }^{8}$ El filósofo alemán puntualiza que esta imagen se encuentra centrada en los bienes y en la distribución, es decir, orientada al receptor. De tal manera que la justicia se centra en el problema de la asignación de bienes, de manera que deja fuera los problemas tanto de producción de los bienes como del establecimiento del esquema de distribución. De esta manera, desde esta imagen, no se pregunta respecto de las condiciones materiales y las relaciones sociales de la producción de los bienes, y tampoco de si el esquema de distribución de los mismos es justo.

Esta primera imagen de la justicia incorpora una concepción muy particular la justicia: la justicia es exclusivamente distributiva o asignativa, es decir, social; no tiene en cuenta

FORST, Rainer; Justificación y crítica. Perspectivas de una teoría crítica de la política, Barcelona: Katz, 2014.

7 Durante la Edad Media, la religión cristiana en occidente operó como dicho discurso ideológico que permitió que el poder injusto no sea cuestionado en masa por la población. En este sentido, la crítica de Marx a esa forma de religión es precisa. Pero esta crítica no alcanza a todas las formas de religión, pues hay formas de esta que tiene en su corazón la deliberación, la igualdad y la dotación de justificación.

8 Forst, Rainer; Justificación y crítica. Perspectivas de una teoría crítica de la política, Barcelona: Katz, 2014. p. 33. El subrayado es mío. 
la justicia política. Su centro de interés está en la distribución de los bienes, no en el examen de los criterios por medio de los cuales estos son distribuidos, y menos aún cuál es el procedimiento político por medio del cual se establece el criterio de distribución. Además, esta primera imagen de la justicia trae consigo una concepción particular del derecho y de los derechos. El derecho es entendido aquí como un esquema de distribución que no se explica de dónde ha surgido, mientras que los derechos son vistos como bienes, entre otros, que se distribuyen de acuerdo al criterio establecido. De esta manera, esta primera imagen de la justicia oculta injusticias políticas y sociales fundamentales.

A su vez, el esquema de distribución es visto como el que asigna de mejor manera bienes y derechos entre las personas para permitir que los individuos puedan desarrollar un tipo de vida de calidad. Pero, lo que significa "calidad de vida" es definido desde el centro distribuidor, suponiendo que los agentes que se encuentran en el centro distribuidor conocen la naturaleza humana y que, en virtud de tal conocimiento, saben lo que desarrolla la vida humana. Incluso, si los agentes que se encuentran en el centro distribuidor asumen la teoría de las capacidades desarrolladas por Amartya Sen y Martha Nussbaum, la situación no cambia, pues se sigue asumiendo cierta concepción de naturaleza humana de acuerdo con la cual estas y no otras son las capacidades humanas básicas ${ }^{9}$. De esta manera, esta imagen de la justicia no solo excluye la justicia política, sino que introduce presupuestos metafísicos como el de naturaleza humana o capacidades humanas básicas. En la teoría de Nussbaum, estas dificultades son patentes porque ella misma considera que su planteamiento se encuentra orientado hacia los resultados en vez de hacia el procedimiento. Una perspectiva de la justicia orientada a los resultados conoce los resultados correctos y solo después busca los procedimientos necesarios que lleven a ellos de la mejor manera posible. Esto es lo que según Rawls denomina: "justicia procedimental imperfecta". Nussbaum señala respecto de las teorías orientadas hacia los resultados o las teorías procedimentales imperfectas que:

[Los defensores de las teorías orientadas al resultado] consideran en general que las doctrinas procedimentales ponen el carro delante del caballo: está claro que lo más importante para la justicia es la calidad de vida de las personas, $y$, por lo tanto, vamos a rechazar cualquier procedimiento, por más elegante que sea, que no nos dé un resultado que encaje con nuestras intuiciones acerca de la dignidad y la equidad. [...] para el teórico orientado al resultado es como si un cocinero les dijera a sus invitados que tiene una máquina sofisticadísima para hacer pasta, la mejor del mercado, y que, por lo tanto, producirá una pasta buena por definición. ${ }^{10}$

Tal como señala Forst, las exigencias de Nussbaum respecto de la justicia fundamental, fundadas en un esquema de capacidades básicas se satisface sin pasar por la justicia política. Basta con que una élite central distribuidora (que ejerza una dictadura benévola) puede satisfacer dichas exigencias, pues ella misma puede distribuir las herramientas necesarias para las condiciones de las capacidades básicas saltando por encima de la justicia política.

\subsection{2.- La segunda imagen de la justicia y del derecho}

La segunda imagen se levanta como crítica de la primera y apunta a un aspecto más profundo. Mientras que la primera se orientaba a los bienes, a la distribución y consideraba a las personas como receptores de la justicia, la segunda se dirige al punto político de la justicia y considera que este es el fundamento de la justicia distributiva. De esta manera, la justicia

\footnotetext{
9 Al respecto, véase NUSSBAUM, Martha; Crear capacidades. Propuesta para el desarrollo humano, Barcelona: Paidós, 2012.

10 NUSSBAUM, Martha; Las fronteras de la justicia. Consideraciones sobre la exclusión, Barcelona: Paidós, 2007. Pp. 94 95.
} 
política es el fundamento de la justicia social y distributiva.

De esta manera, señala Forst que:

[E]l concepto de justicia posee un núcleo de significado que tiene como concepto contrapuesto esencial el de la arbitrariedad: sea ya el dominio arbitrario de individuos, sea el de una parte de la comunidad (por ejemplo de una clase), sea la aceptación de contingencias sociales que conducen a posiciones $\mathrm{o}$ condiciones asimétricas de dominación $y$ que son aceptadas como impuestas por el destino e inmodificables, sin serlo... [Así], el impulso básico contra la injusticia no es primordialmente el de querer tener algo o algo más sino el de no querer seguir siendo dominado, acosado o ignorado en la pretensión y el derecho fundamental a la justificación. ${ }^{11}$

De esta manera, Forst señala, en primer lugar, que la justicia se opone a la arbitrariedad. De manera que la justicia, en un sentido fundamental, es la ausencia de arbitrariedad. Y, en segundo lugar, la arbitrariedad política es la dominación que hace caso omiso al derecho fundamental a la justificación. Así, la exigencia básica de la justicia no es tener más o querer tener más, sino el no ser dominado. La justicia no es una relación entre persona cosa, sino un tipo especial de relación entre personas que excluye la dominación arbitraria. La justicia es fundamentalmente política. La justicia política no se centra en la asignación de bienes y derechos, sino que su corazón reside en el debate respecto de los criterios de asignación. Para participar de ese debate, es necesario que a nadie se le niegue el derecho fundamental a la justificación. De esta manera, la tarea del derecho es la de institucionalizar dicho derecho, es decir, generar las condiciones institucionales para que el derecho a la justificación sea posible y nadie quede excluido de dicho derecho.

La segunda imagen muestra con claridad que la relación entre la justicia política y la justicia social y distributiva es de tal manera que la primera es la base de la segunda. No solo sucede que la justicia social y distributiva es posible si se garantiza la justicia política, sino que la justicia social deriva de la justicia política. Y, puesto que la justicia social o distributiva asigna bienes $y$ derechos, el derecho debe ser entendido como un derivado de la justicia política.

\section{4.- Conclusión}

Si la justicia política es la base del derecho,eso significa que la conexión entre el derecho y la justicia es la siguiente: el derecho es un fenómeno de la política, es decir, el derecho es derivado de la política. En este sentido, la tesis del positivismo (que defiende la autonomía del discurso jurídico) es falsa. Pero también es falsa una posición como la de Carlos Santiago Nino, según la cual el derecho y la política se encuentran en un punto de intersección.

Ciertamente, esta conclusión puede estremecer los corazones de los juristas, puesto que ven en esta la decisión de dejar el derecho y la justicia en manos de la arbitrariedad de quien cuenta con el poder político. Pero esta reacción solo es fruto del hecho de que la reflexión sobre el derecho y la política no ha sido suficientemente desplegada. Pero una filosofía política reflexiva puede despejar aquel temor con toda tranquilidad. Así, el afirmar que el derecho es un fenómeno de la política no deja todo en mano de la arbitrariedad. $\mathrm{Si}$ consideramos que en el centro de la política se encuentra instalado el derecho a la justificación, entonces la protección frente a la arbitrariedad de los poderosos se encuentra suficientemente garantizada.

11 FORST, Rainer; Justificación y crítica. Perspectivas de una teoría crítica de la política, Barcelona: Katz, 2014. p. 35. 


\section{REFERENCIAS}

Alexi, Robert, (1997) El concepto y la validez del derecho, Barcelona: Gedisa.

Alexi, Robert, (2008) Teoría de los derechos fundamentales, Madrid: Centro de Estudios Políticos y Constitucionales.

Austin, John, (1861) Lectures of Jurisprudence: Or The Philosphy of Possitive Law, Londres. P. 88.

Austin, John, (1981) Sobre la utilidad de la jurisprudencia, Madrid: Centro de Estudios Constitucionales.

Forst, Rainer, (2014) Justificación y crítica. Perspectivas de una teoría crítica de la política, Barcelona: Katz.

Forst, Rainer, (2014) The Rigth to Justification. Elements of a Constructivist Theory of Justice, Columbia University Press.

Kelsen, Hans, (1983) Teoría pura del derecho, México: UNAM.

Luhmann, Niklas, (1998) Sistemas sociales. Lineamientos para una teoría general, Barcelona: Anthopos.

Nino, Carlos Santiago, (1994) Derecho, moral y política: una revisión de la teoría general del derecho, Barcelona: Editorial Ariel.

Nussbaum, Martha, (2012) Crear capacidades. Propuesta para el desarrollo humano, Barcelona: Paidós.

Nussbaum, Martha, (2007) Las fronteras de la justicia. Consideraciones sobre la exclusión, Barcelona: Paidós.

Pozzolo, Susanna, (2011) Neoconstitucionalismo y positivismo jurídico, Lima: Palestra.

Fecha de recepción: 08-03-16

Fecha de aceptación 12-04-16 